\title{
Statistical study on interplanetary drivers behind intense geomagnetic storms and substorms
}

\author{
Tian Tian' ${ }^{1}$, Zheng Chang2 ${ }^{2 *}$, LingFeng Sun ${ }^{1}$, JunShui Bai ${ }^{1}$, XiaoMing Sha', and Ze Gao ${ }^{1}$ \\ ${ }^{1}$ Mailbox 5111, Beijing 100094, China; \\ ${ }^{2}$ National Space Science center, Chinese Academy of Sciences, Beijing 100190, China
}

\begin{abstract}
Geomagnetic storms and substorms play a central role in both the daily life of mankind and in academic space physics. The profiles of storms, especially their initial phase morphology and the intensity of their substorms under different interplanetary conditions, have usually been ignored in previous studies. In this study, 97 intense geomagnetic storms $\left(D s t_{\min } \leq-100 \mathrm{nT}\right.$ ) between 1998 and 2018 were studied statistically using the double superposed epoch analysis (DSEA) and normalized superposed epoch analysis (NSEA) methods. These storms are categorized into two types according to different interplanetary magnetic field (IMF) $B_{z}$ orientations: geomagnetic storms whose IMF is northward, both upstream and downstream relative to the interplanetary shock, and geomagnetic storms whose upstream and downstream IMF is consistently southward. We further divide these two types into two subsets, by different geomagnetic storm profiles: Type I/Type II — one/two-step geomagnetic storms with northward IMF both upstream and downstream of the interplanetary shock; Type III/TypeIV — one/two-step geomagnetic storms with southward IMF both upstream and downstream of the interplanetary shock. The results show that: (1) geomagnetic storms with northward IMF both upstream and downstream of the interplanetary shock have a clear initial phase; geomagnetic storms with southward IMF in both upstream and downstream of the interplanetary shock do not; (2) the IMF is an important controlling factor in affecting the intensity characteristics of substorms. When $B_{z}$ is positive before and after the interplanetary shock arrival, the Auroral Electrojet $(A E)$ index changes gently during the initial phase of geomagnetic storms, the median value of $A E$ index is maintained at 500-1000 nT; (3) when $B_{z}$ is negative before and after the interplanetary shock arrival, the $A E$ index rises rapidly and reaches its maxmum value about one hour after storm sudden commencements (SSC), although the time is scaled between reference points and the maximum value of $A E$ is usually greater than 1,000 $\mathrm{nT}$, representing intense substorms; (4) for most cases, the $D s t_{0}$ usually reaches its minimum at least one hour after $B_{z}$. These results are useful in improving contemporary space weather models, especially for those that address geomagnetic storms and substorms.
\end{abstract}

Keywords: geomagnetic storms; substorms; normalized superposed epoch analysis; initial phase; IMF $B_{z}$

Citation: Tian, T., Chang, Z., Sun, L. F., Bai, J. S., Sha, X. M., and Gao, Z. (2019). Statistical study on interplanetary drivers behind intense geomagnetic storms and substorms. Earth Planet. Phys., 3(5), 380-390. http://doi.org/10.26464/epp2019039

\section{Introduction}

Geomagnetic storms and substorms are important space weather phenomena and an intensely active space weather research topic. Many investigators have studied geomagnetic storms and substorms (e.g., Akasofu and Chapman, 1963; Lakhina et al., 2006; Russell et al., 1974; Partamies et al., 2011). It is well known that substorms can occur during super storms and intense storms, or even independently of storms (Hajra et al., 2016; Partamies et al., 2013; Tsurutani et al., 2015). Hajra et al. (2016) studied supersubstorm (SSS) events from 1981 to 2012 by using superposed epoch analysis (SEA) and found that $86.5 \%$ of the SSS events occurred in the main phase of geomagnetic storms and about $9.5 \%$ occurred in the recovery phase. Recently, study of space weather conditions for SSS events has attracted increased attention; it has been noted that SSS events appear to be associated with enhanced val-

Correspondence to: Z. Chang, changzh@nssc.ac.cn

Received 10 MAY 2019; Accepted 12 JUN 2019.

Accepted article online 11 JUL 2019.

(C)2019 by Earth and Planetary Physics. ues of solar wind speed and with southward direction of the interplanetary magnetic field (IMF) (Tsurutani et al., 2015; Zhou XY and Tsurutani, 2001). Yue C et al. (2010) and Ma XH et al. (2019) reported that interplanetary (IP) shocks with southward IMF preconditions can significantly enhance Auroral Electrojet $(A E)$ indices, while no obvious $A E$ index enhancements are observed when IP shock events occur under northward IMF preconditions.

For geomagnetic storms, many studies have focused on the relationship between the intensity of geomagnetic storms and interplanetary sources and/or on causes of the one-step/two-step morphology of the main phases of geomagnetic storms (Akasofu and Chapman, 1963; Russell et al., 1974; Srivastava and Venkatakrishnan, 2004; Le GM et al., 2010; Zhao H et al., 2011). It is now well established that intense geomagnetic storms $\left(D s t_{\min } \leq 100 \mathrm{nT}\right)$ are caused mainly by coronal mass ejections (Brueckner et al., 1998; Gonzalez et al., 1999; Cane et al., 2000; Gopalswamy et al., 2000; Zhang J et al., 2003), while moderate and weak storms can be caused by high-speed streams in corotating interaction regions (Gosling et al., 1991; Tsurutani and Gonzalez, 1997). Some re- 
searchers have classified geomagnetic storms as either one- or two-step by their profiles and have studied the interplanetary magnetic field, pointing out that the steps of the time varying Dst during storms result primarily from different structures of the interplanetary solar wind (Kamide et al., 1998; Dessler and Parker, 1959; Tsurutani and Gonzalez, 1997; Richardson and Zhang J, 2008).

A typical geomagnetic storm has three phases: an initial phase, a main phase, and a recovery phase (Gonzalez et al., 1994). The initial phase is characterized by increases of 20 to $50 \mathrm{nT}$ in Dst (or in its one-minute component SYM-H) in tens of minutes. The initial phase often begins with an abrupt increment of Dst referred to as a storm sudden commencement (SSC). As mentioned previously, most studies of geomagnetic storms have focused on the storms' intensities or main phases. The initial phases of geomagnetic storms under different interplanetary conditions, and corresponding substorm characteristics, are rarely studied.

SEA is a powerful method for studying the time variation of geomagnetic storms. However, Yermolaev et al. (2010a) pointed out that by using only SEA the interplanetary causes of magnetic storm onset cannot be investigated, since the duration of the storm main phase can vary between 2 and 15 hours, the average duration being approximately $7 \mathrm{~h}$ (Vichare et al., 2005; Gonzalez and Echer, 2005; Yermolaev et al., 2007, 2010b). In order to remove SEA's drawbacks these investigators developed a double superposed epoch analysis (DSEA) method. Then, by applying the DSEA method, they presented a comprehensive study of plasma and solar wind properties for different categories.

Similar to SEA and DSEA (Yermolaev et al., 2010a, b), normalized superposed epoch analysis (NSEA) is a statistical analysis method for time series with three or more reference times. In this paper, by using the DSEA and NSEA methods, we systematically analyze the properties of the interplanetary magnetic field, solar wind parameters, and the dawn-dusk electric field that are associated with geomagnetic storms and substorms. We focus primarily on the morphology of the storms' initial phase and on the intensity of substorms under different interplanetary conditions, details that have tended to be ignored in previous studies.

This study is organized as follows: first, we analyze four typical geomagnetic storms events: one-step geomagnetic storms on June 26, 1998 / August 06, 1998 with northward/southward IMF in both upstream and downstream regions of the IP shock, and twostep geomagnetic storms on May 4, 1998/May 8, 2005 with northward/southward IMF in both upstream and downstream regions of the IP shock. Then we use DSEA and NSEA to analyze the properties of IP parameters for four typical geomagnetic storms: Type I/Type II (one/two-step geomagnetic storms with northward IMF both upstream and downstream of the IP shock), Type III/Type IV (one/two-step geomagnetic storms with southward IMF both upstream and downstream of the IP shock).

\section{Data Set and Methodology}

Geomagnetic storms are caused primarily by sufficiently intense, long-duration, southward IMF, associated with intense and longlasting interplanetary electric fields (Gonzalez et al., 1994; O’Brien and McPherron, 2000; Farrugia et al., 2006). Xie $\mathrm{H}$ et al. (2006) pointed out that there is a good correlation among $D s t_{\min }, B_{z}$, and $V B_{z}$. The correlation coefficient between $D s t_{\min }$ and $B_{z}$ dips in longlived geomagnetic storms is 0.77 and 0.79 particularly in the main phases. Wu CC and Lepping (2002) noticed that the occurrence timing of storm intensity is highly correlated with the occurrence timing of minimum $B_{z}$ (maximum $V B_{z}$ ) for a magnetic cloud with field rotating southward to northward.

In this paper, we focus mainly on analyzing the interplanetary magnetic field, solar wind parameters, the dawn-dusk electric field based on 1-min OMNI data (ftp://spdf.gsfc.nasa.gov/pub/data/ omni/high_res_omni/sc_specific/), and geomagnetic indices (http://wdc.kugi.kyoto-u.ac.jp/wdc/Sec3.html). By applying the DSEA and NSEA methods, we studied 97 intense geomagnetic storms events $\left(D s t_{\min } \leq-100 \mathrm{nT}\right.$ ) from 1998-2018. We classified these events into two types according to different IMF $B_{z}$ orientations: geomagnetic storms with northward IMF both upstream and downstream of the IP shock, and geomagnetic storms with southward IMF both upstream and downstream of the IP shock. We divide these two types further into two subsets according to how the Dst reaches the minimum the main phase. Type I - one-step geomagnetic storms with positive IMF $B_{z}$ in both upstream and downstream of the IP shock. Type II - two-step geomagnetic storms with positive IMF $B_{z}$ in both upstream and downstream of the IP shock. Type III - one-step geomagnetic storms with negative IMF $B_{z}$ in both upstream and downstream of the IP shock. Type IV - two-step geomagnetic storms with negative IMF $B_{z}$ in both upstream and downstream of the IP shock. In our database, there are 32 Type I storms, 15 Type II storms, 28 Type III storms, 13 Type IV storms and only 9 cases whose type could not be identified. One-step geomagnetic storms represent a typical magnetic storm, consisting of a main phase during which Dst decreases monotonously and a subsequent recovery phase. Two-step geomagnetic storms are characterized by a two-step decrease in the value of Dst. To identify one/two-step storms, we used the criteria innovated by Kamide et al. (1998).

To apply the NSEA method, one of the key issues is choosing reference times (Yermolaev et al., 2010a, b). For Type I and Type III we have chosen as our two reference points the storm onset (time "0") and the time of the Dst index minimum (time "6"). For Type II and Type IV, besides time " 0 " (the time at which the Dst index reaches its minimum during the first step) and time " 6 " (the time at which the Dst index reaches its minimum during the second step), we choose the storm onset (time " -6 ") as another reference point. For all events, the time series between time " 0 " and time " 6 " or between time " -6 " and time " 0 " is divided equally into 5 subintervals and the data in each subinterval are averaged. The time scale before the first reference point and after the last reference point remains unchanged. These artificially similar events are then grouped according to epoch time. Finally, we treat the $25^{\text {th }}$ percentile, the $50^{\text {th }}$ percentile (i.e., the median) and the $75^{\text {th }}$ percentile as average statistical properties of the different parameters.

\section{Case Study}

For the case study, we have selected four typical geomagnetic storms (one-step geomagnetic storms on June 26, 1998 / August 
06, 1998 with northward/southward IMFs both upstream and downstream of the IP shock, and two-step geomagnetic storms on May 4, 1998 / May 8, 2005 with northward/southward IMFs both upstream and downstream of the IP shock) to illustrate the events selected in the four different geomagnetic storms types, which are shown in Figure 1 and Figure 2, respectively.

Figure 1 shows the solar wind conditions based on OMNI data, the SYM- $\mathrm{H}$, the Dst, and the $A E$ variation for Type I magnetic storm $\left(D s t_{\min }=-101 \mathrm{nT}\right)$ on June 26, 1998 and Type III geomagnetic storm $\left(D s t_{\min }=-138 \mathrm{nT}\right.$ ) on August 06, 1998. From top to bottom the panels plotted are the plasma temperature, density, velocity, dynamic pressure, the magnetic field intensity, the dawn-dusk electric field, the IMF $B_{Z}$, the SYM- $\mathrm{H}$, the original geomagnetic index Dst, the pressure-corrected $D s t_{0}$, and the $A E$ index. The light green area represents the initial phase and the purple area repres-

(a) 1998/06/26 one-step storm, $B_{z}$ from "+" to "+"

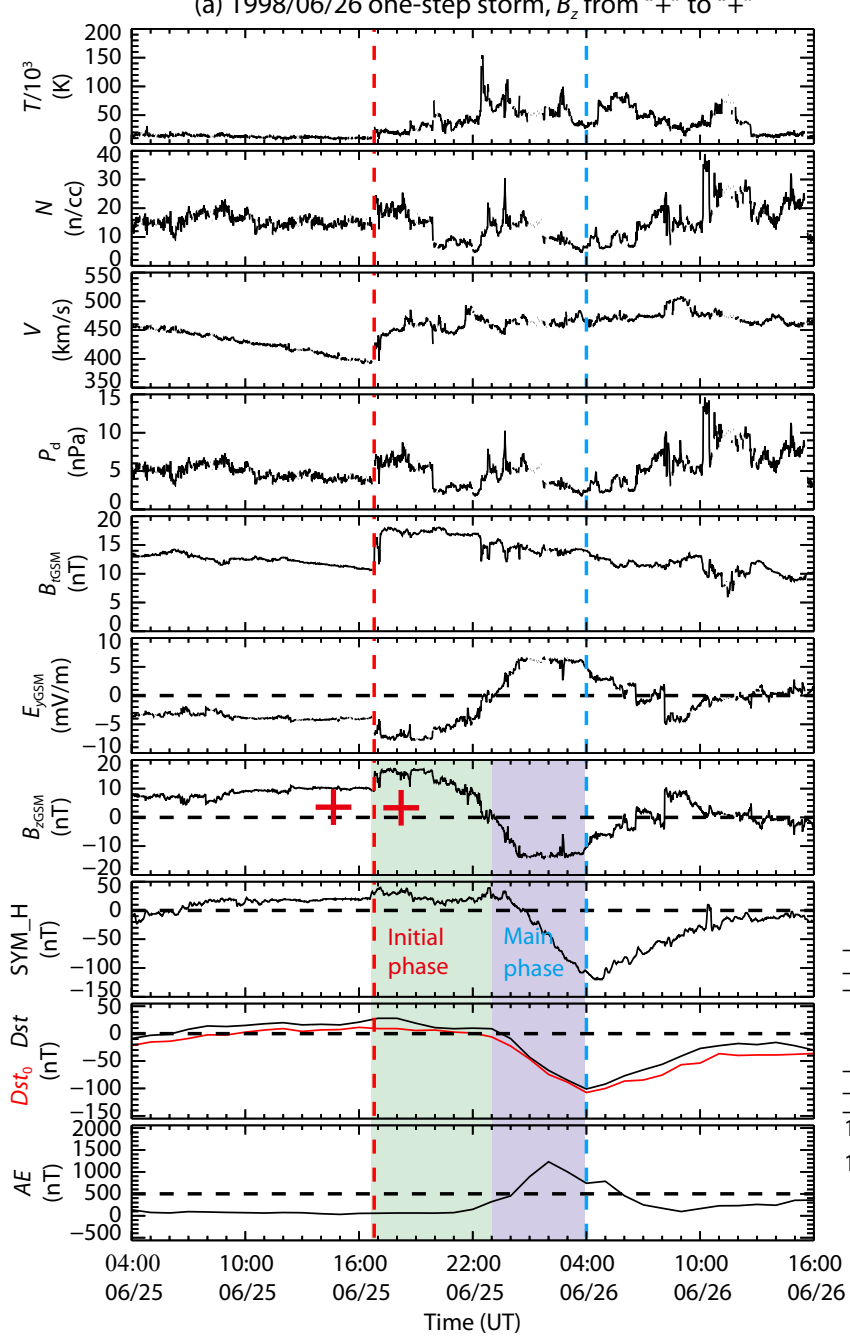

ents the main phase of the storm. The red vertical dashed line denotes the time of shock arrival. The time when Dst reaches its minimum is denoted by the sky-blue vertical dashed line. According to Burton's empirical equation (1) (Burton et al., 1975), we calculated the pressure-corrected $D s t_{0}$ shown in Panel 9 for each event in Figure 1.

$$
\begin{aligned}
& D s t_{0}=D s t-b(p)^{1 / 2}+c, \\
& \frac{\mathrm{d} D s t_{0}}{\mathrm{~d} t}=F(E)-a D s t_{0}
\end{aligned}
$$

Where $E=V B_{z} \times 10^{-3}(\mathrm{mV} / \mathrm{m})$ and $p=n v^{2} \times 10^{-3}\left(\mathrm{eV} / \mathrm{cm}^{-3}\right), F(E)$ is the injection function, $B_{z}$ is the southward IMF, $V$ is the solar wind velocity, $p$ is the dynamic pressure, and the coefficients $a$ and $b$ are constants. The coefficient $a$, which measures the ring current decay, has the value of $3.6 \times 10^{-5} \mathrm{~s}$; the coefficient $b$, which meas-

(b) 1998/08/06 one-step storm, $B_{z}$ from "-" to "-"

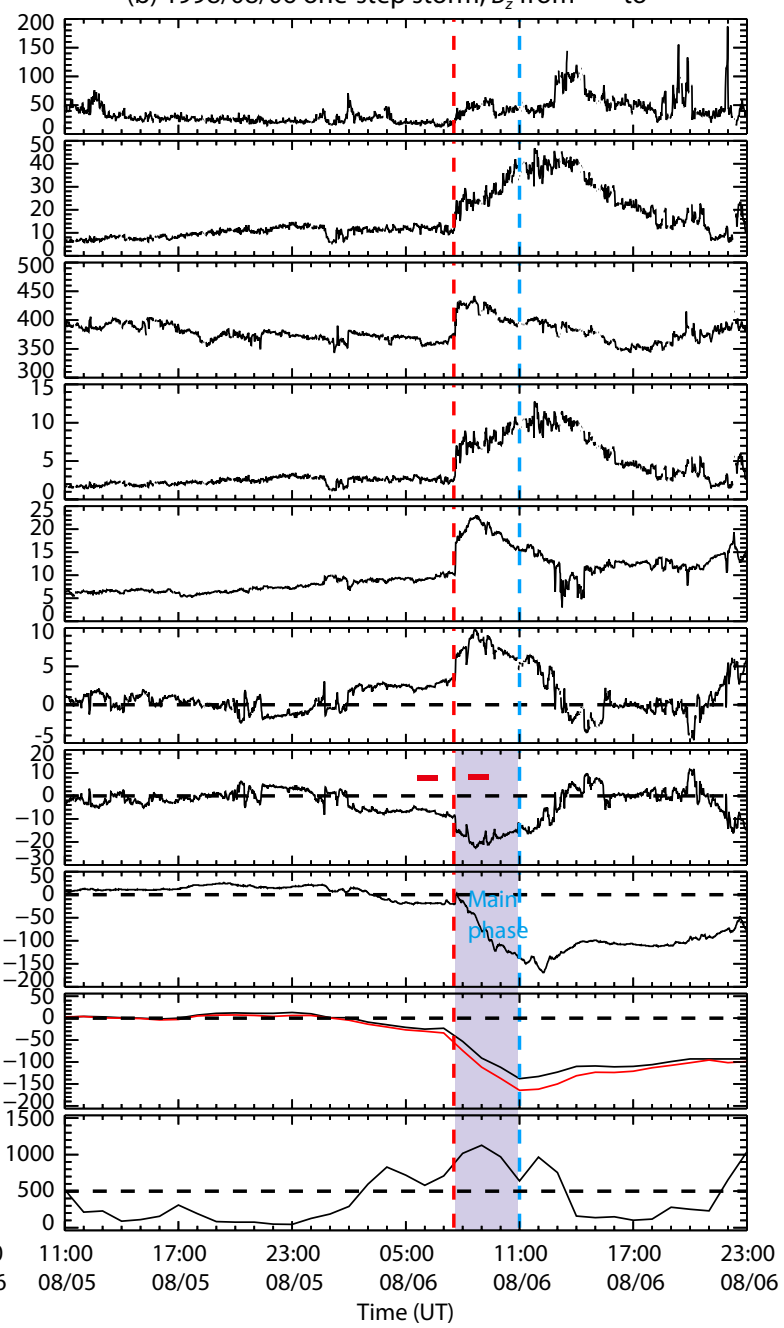

Figure 1. Two cases of one-step magnetic storm with northward/southward IMF both upstream and downstream of the IP shock. From top to bottom the panels plotted are the plasma temperature, density, velocity, dynamic pressure, the magnetic field intensity, the dawn-dusk electric field, the IMF $B_{z}$, the SYM-H, the $D s t$ index, the pressure-corrected $D s t_{0}$, and the $A E$ index. The red vertical dashed line denotes the shock arrival time. The time when $D s t$ reaches its minimum is denoted by the sky-blue vertical dashed line. The light green area represents the initial phase. The purple area represents the main phase. (a) One-step geomagnetic storm on June 26, 1998 with northward IMF $B_{z}$ both upstream and downstream of the IP shock. (b) One-step geomagnetic storm on August 06, 1998 with southward IMF $B_{z}$ both upstream and downstream of the IP shock. 
(a) 1998/05/04 two-step storm, $B_{z}$ from " + " to " + "

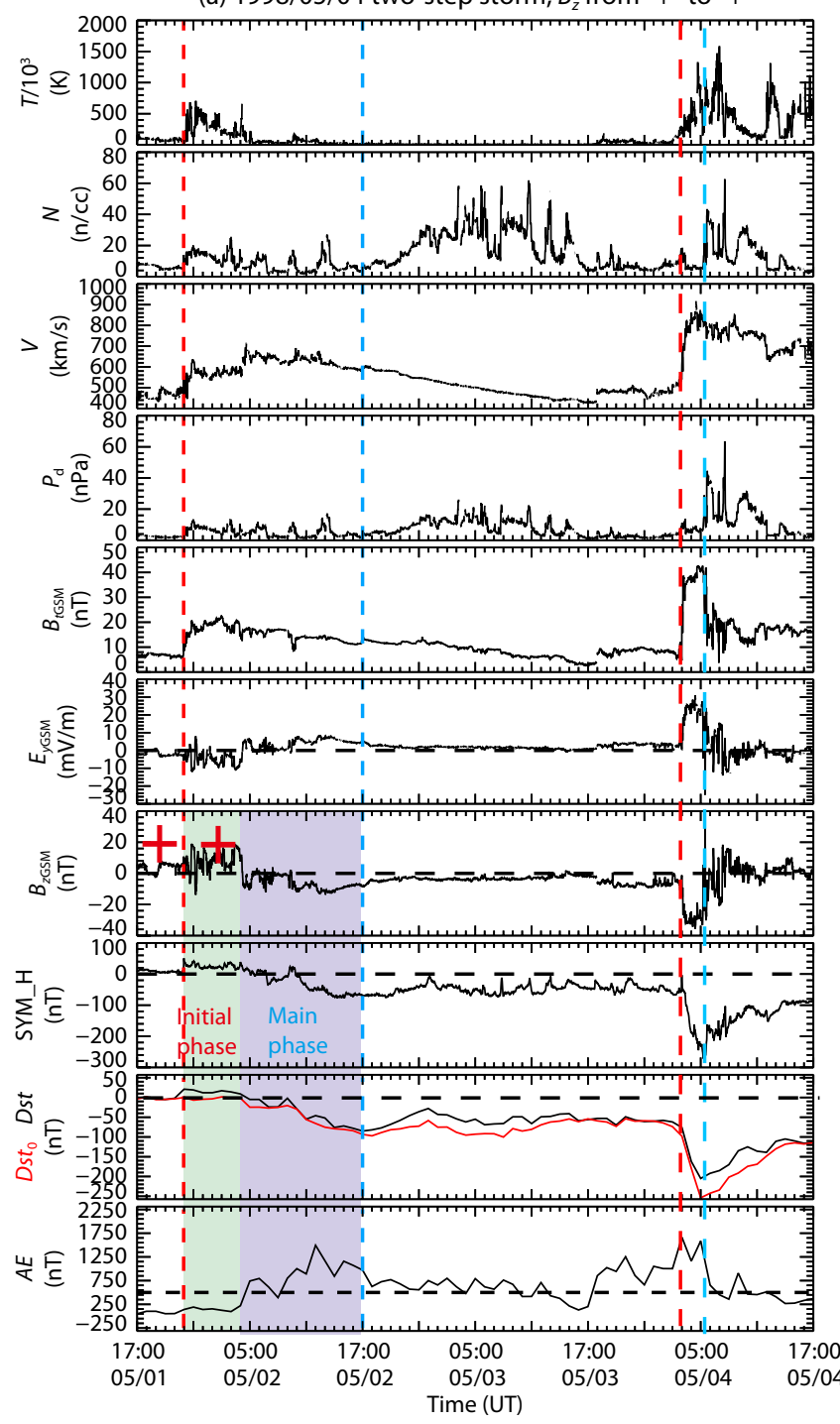

(b) 2005/05/08 two-step storm, $B_{z}$ from " -" to " -"

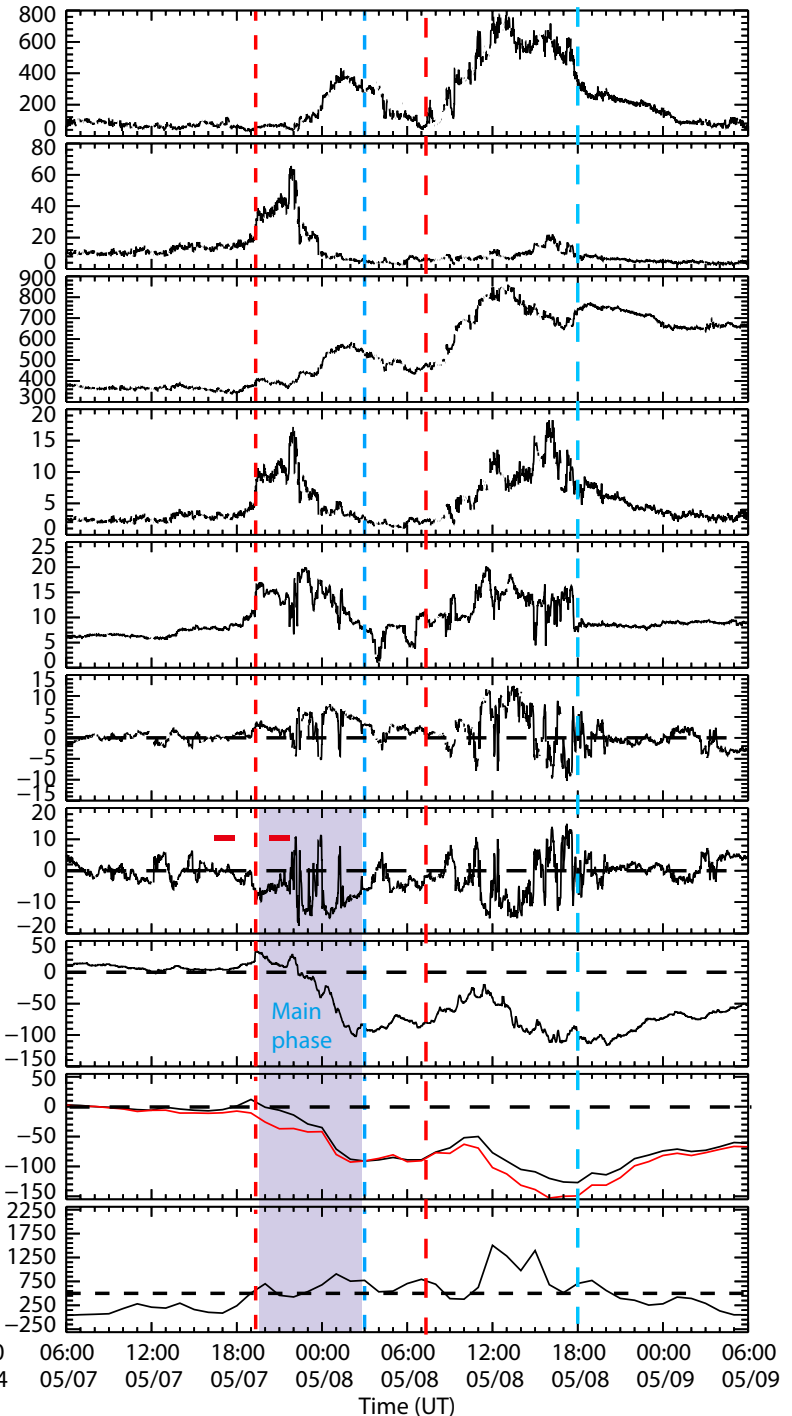

Figure 2. Two cases of two-step geomagnetic storms with northward/southward IMF both upstream and downstream of the IP shock. (a) Twostep geomagnetic storm on May 4, 1998 with northward IMF both upstream and downstream of the IP shock. (b) Two-step geomagnetic storm on May 8, 2005 with southward IMF both upstream and downstream of the IP shock. The format is similar to Figure 1.

ures the correlation between the corrected Dst and dynamic pressure, has the value of $0.20 \mathrm{nT} /\left(\mathrm{eV} \cdot \mathrm{cm}^{-3}\right)^{-1 / 2}$.

In Figure 1a, the IMF $B_{z}$ remained positive both before and after the time of shock arrival (at 16:48 UT), as it increased from 8 to 18 $\mathrm{nT}$. Meanwhile, the $E_{y}$ decreased from -3 to $-7 \mathrm{mV} / \mathrm{m}$ and the SYM-H increased from 20 to $43 \mathrm{nT}$. In the following interval (between 16:48 and 23:00 UT), $B_{z}$ remained positive and $E_{y}$ remained negative, with no ring current injection, and the higher value of SYM-H persisted; this completed the initial phase. Meanwhile, the $A E$ index remained at 0-100 nT. After 23:00 UT, $B_{z}$ rotated from positive to negative, $E_{y}$ became positive and produced current injection, and thus induced the main phase of the magnetic storm, during which $A E$ increased from 72 to $1232 \mathrm{nT}$, reaching its maximum, the level of intense substorm, 10 hours after SSC.

The penultimate panel of Figure 1a shows the original Dst and pressure-corrected $D s t_{0}$. The dynamic pressure began to increase from 16:48 UT, with the contribution of magnetopause current leading to $D s t$ index increases, while the $D s t_{0}$ basically did not change. After 23:00 UT, the variations of $D s t$ and $D s t_{0}$ versus time are similar, and we focus mainly on the variation of pressure-corrected $D s t_{0}$. The peak of the storm is driven by long-playing southward directed magnetic fields $\left(B_{z}<0\right)$, which produced prolonged positive $E_{y}$, ring current injection. As a result, the main phase began and reached the minimum at 04:00 UT.

For comparison, a one-step geomagnetic storm on August 06, 1998 with southward IMF in both upstream and downstream regions of the IP shock is shown in Figure $1 \mathrm{~b}$. In this event, $B_{z}$ decreased from -10 to $-18 \mathrm{nT}$ after the shock arrival (at 07:32 UT) and the $E_{y}$ increased from 3 to $7 \mathrm{mV} / \mathrm{m}$. The SYM-H increased from -20 to $0 \mathrm{nT}$ then gradually decreased. The $A E$ index reached the moderate substorm level at the shock arrival, and reached the intense substorm level $(A E=1128 \mathrm{nT})$ during the magnetic storm. The maximum value of the $A E$ index appeared 1.5 hours after SSC. Between the time of shock arrival and the time of Dst reaching its 
minimum (at 11:00 UT), the $B_{z}$ remained negative; $E_{y}$ remained positive, producing current injection that drove $D s t$ to a main phase minimum of $-138 \mathrm{nT}$ directly, without an initial phase.

It can be seen from Figure 1 that, under southward IMF condition, the August 06, 1998 event affected the geomagnetic indices more than did the June 26, 1998 event. This observation is consistent with the results of Yue C and Zong QG (2011). The Type I storm in this case study had a clear initial phase while the Type III storm did not. The Burton equation can explain this difference. From the time of shock arrival to the time of $D s t_{\min }$ in the Type I case, $E_{y}$ changed from negative to positive, resulting in a clear initial phase and then a main phase. In the Type III case, however, a continuous positive $E_{y}$ produced ring current injection that drove Dst to a main phase minimum of $-138 \mathrm{nT}$. We can also see from Figure 1 that when $B_{z}$ is negative before and after the arrivald of the IP shock, the $A E$ index will rise rapidly. An intense substorm will be triggered in 1-2 hour.

It is worth noticing that the time of minimum $D s t_{0}$ is not identical to the time of minimum $B_{z}$, which again the Burton equation can readily explain; this will be analyzed in detail in the discussion section.

Figure $2 \mathrm{a}$ and $2 \mathrm{~b}$ show the solar wind conditions based on OMNI data, the SYM- $\mathrm{H}$, the Dst, and the $A E$ variation for the Type II magnetic storm $\left(D s t_{\min }=-149 \mathrm{nT}\right)$ on May 4, 1998 and the Type IV geomagnetic storm $\left(D s t_{\min }=-138 \mathrm{nT}\right)$ on May 8,2005 . The light green area represents the initial phase and the purple area represents the main storm phase. Here the first and second sky-blue lines represent the Dst minima at different steps of the storm; the red lines represent the shock arrival time.

As we can see from Figure 1 and the first step of the storm in Figure 2, similar results can be found for the IP shock associated with a given IMF $B_{z}$ variation. In theType II case, the IMF $B_{z}$ remained positive both before and after the time of the first shock arrival, maintaining a higher value of SYM-H and defining the initial phase. At 04:00 UT, $B_{z}$ rotated from positive to negative; $E_{y}$ became positive and produced current injection, and thus induced the main phase of the magnetic storm. In the Type IV case, the IMF $B_{z}$ remained negative both before and after the time of shock arrival, and then $B_{z}$ remained negative until the time at which Dst reaches its minimum (at 03:00 UT). As a result, $E_{y}$ remained positive and produced current injection that drove Dst directly to its main phase minimum of $-100 \mathrm{nT}$, without an initial phase.

The variation characteristics of the $A E$ index were similar to those in Figure 1. During the initial phase of the geomagnetic storm, $A E$ $\leq 500 \mathrm{nT}$. During the main phase of the magnetic storm, the $A E$ index rose to $500 \mathrm{nT}$, and the maximum value exceeded even 1,000 $\mathrm{nT}$, triggering the intense substorm.

\section{Statistical Study}

In Section 3, four case studies indicate that the properties of interplanetary magnetic field, solar wind parameters, ring current injection, and the Dst and $A E$ indices are obviously different among the different types. In this section, we use DSEA and NSEA methods to examine the characteristics of interplanetary parameters and geomagnetic indices for different types of geomagnetic storm events. Figure 3 illustrates the results of a DSEA for Type I and Type III geomagnetic storms. Figure 4 illustrates the results of an NSEA for Type II and Type IV geomagnetic storms. Black, red, and blue lines mark the $25^{\text {th }}$ percentile, $50^{\text {th }}$ percentile and $75^{\text {th }}$ percentile values, respectively.

In Figure 3a, the median value of IMF remained northward both before and after the time of shock arrival (time " 0 "), as it increased from 1 to 8 nT. Next, at approximately " 3 " h, it dropped down to zero and reached its minimum (around $-20 \mathrm{nT}$ ) near time " 6 ". Meanwhile, the median value of the SYM-H index increased from 0 to $20 \mathrm{nT}$, and then maintained a higher value in the time range " $0-3$ ", leading to the initial phase. In the initial phase, the $A E$ index increased slowly and was less than $500 \mathrm{nT}$. This is consistent with the results of the case study. SYM-H began to drop down near time " 3 " and reached its minimum -147 nT near time " 6 ", which caused the main phase. During this period, the $A E$ index rose and remained at 500-1000 nT. The median value of the solar wind speed changed from 400 to $500 \mathrm{~km} / \mathrm{s}$, then showed no change in the time interval " $0-6$ ". The median values of the plasma temperature, density, dynamic pressure and magnetic field intensity all increased abruptly at the time of shock arrival. The dynamic pressure and magnetic field intensity remained approximately constant in the time interval "3-6". The plasma temperature and density both increased in the interval "0-3", slowly decreasing in the interval "3-6".

As can be seen from Figure 3b, the median value of IMF remained southward both upstream and downstream of the IP shock, as it decreased from -2 to $-10 \mathrm{nT}$ and reached -10 nT near time "1". Meanwhile, the $A E$ index rapidly increased from 400 to $1,027 \mathrm{nT}$. The median value of the SYM-H index increased from -10 to $10 \mathrm{nT}$ at time " 0 ", then decreased from 10 to $-133 \mathrm{nT}$, reaching its minimum at time " 6 ", which caused the main phase. The median value of the solar wind speed changed from 380 to $500 \mathrm{~km} / \mathrm{s}$, and then showed small changes in the time interval " $0-6$ ". The median values of dynamic pressure and the magnetic field intensity showed similar behaviors as those in Figure 3a. In the time interval "0-6", the median value of density remained high ( 20 n/cc) while the median value of the plasma temperature decreased.

In addition to the above differences, we can also obviously find that when $B_{z}$ is positive before and after the IP shock arrival, the $A E$ index changes gently during the initial phase of geomagnetic storms; and, usually, the median value of the $A E$ index is less than $500 \mathrm{nT}$. When $B_{z}$ is negative before and after the IP shock arrival, the $A E$ index rises rapidly and usually reaches its maxmum an hour after SSC, triggering intense substorms, although the time is scaled between reference points. The result is consistent with the case study in Figure 1.

In Figure 4a, the median value of IMF remained northward both before and after the time of the first shock arrival (time " -6 "), as it increased from 1 to $8 \mathrm{nT}$, Meanwhile, the median value of the SYM$\mathrm{H}$ index increased from -20 to $0 \mathrm{nT}, P_{\mathrm{d}}$ increased from 3 to $8 \mathrm{nPa}$, and the solar wind speed changed from 450 to $500 \mathrm{~km} / \mathrm{s}$. $E_{y}$ decreased from 2 to $-3 \mathrm{mV} / \mathrm{m}$. In the interval time " -6 to -3 ", the solar wind speed changed slightly, the median value of $B_{z}$ remained 
(a) Type l: one-step storm, $B_{z}$ from " + " to " + "

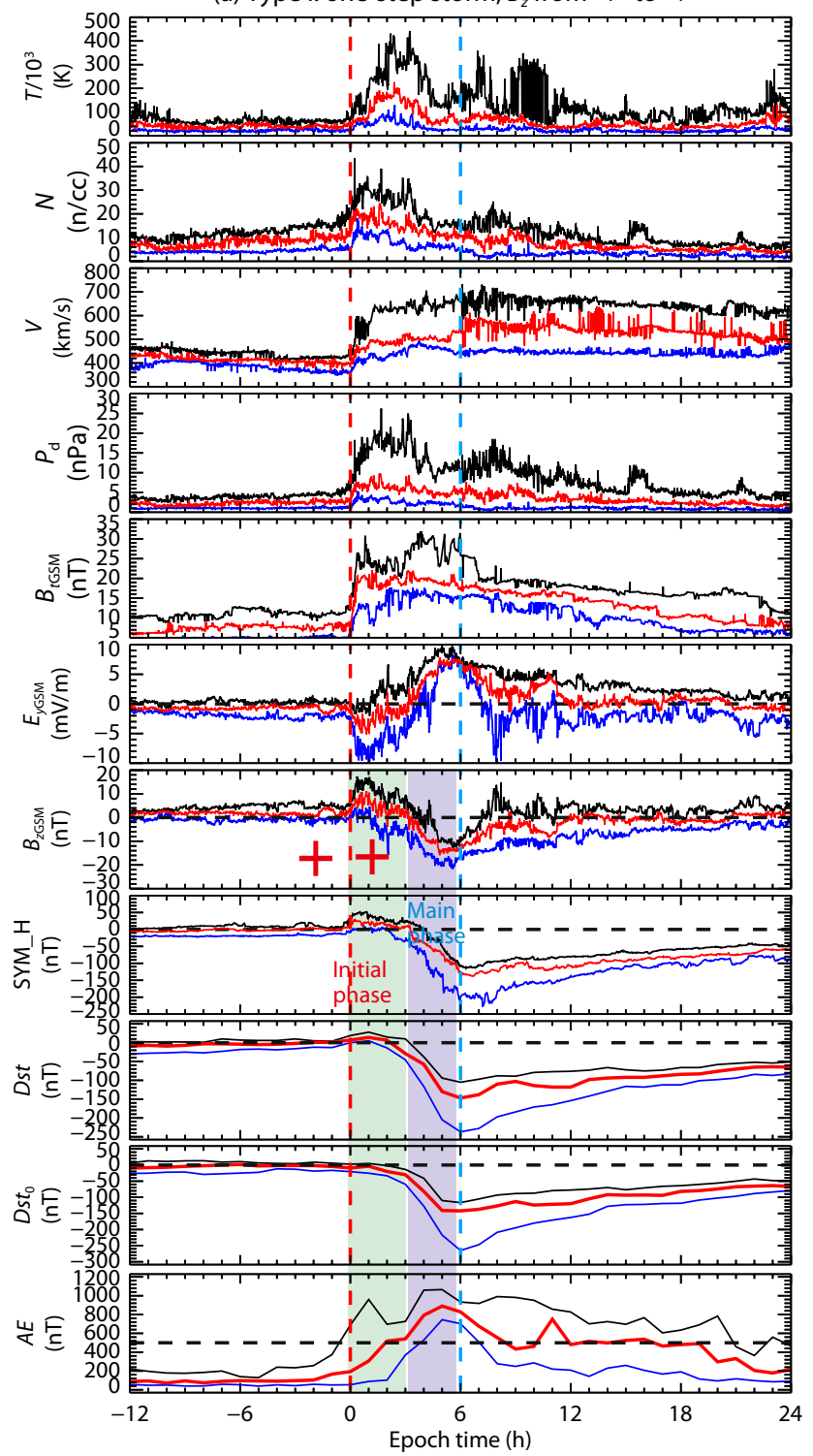

(b) Type III: one-step storm, $B_{z}$ from "-" to "-"

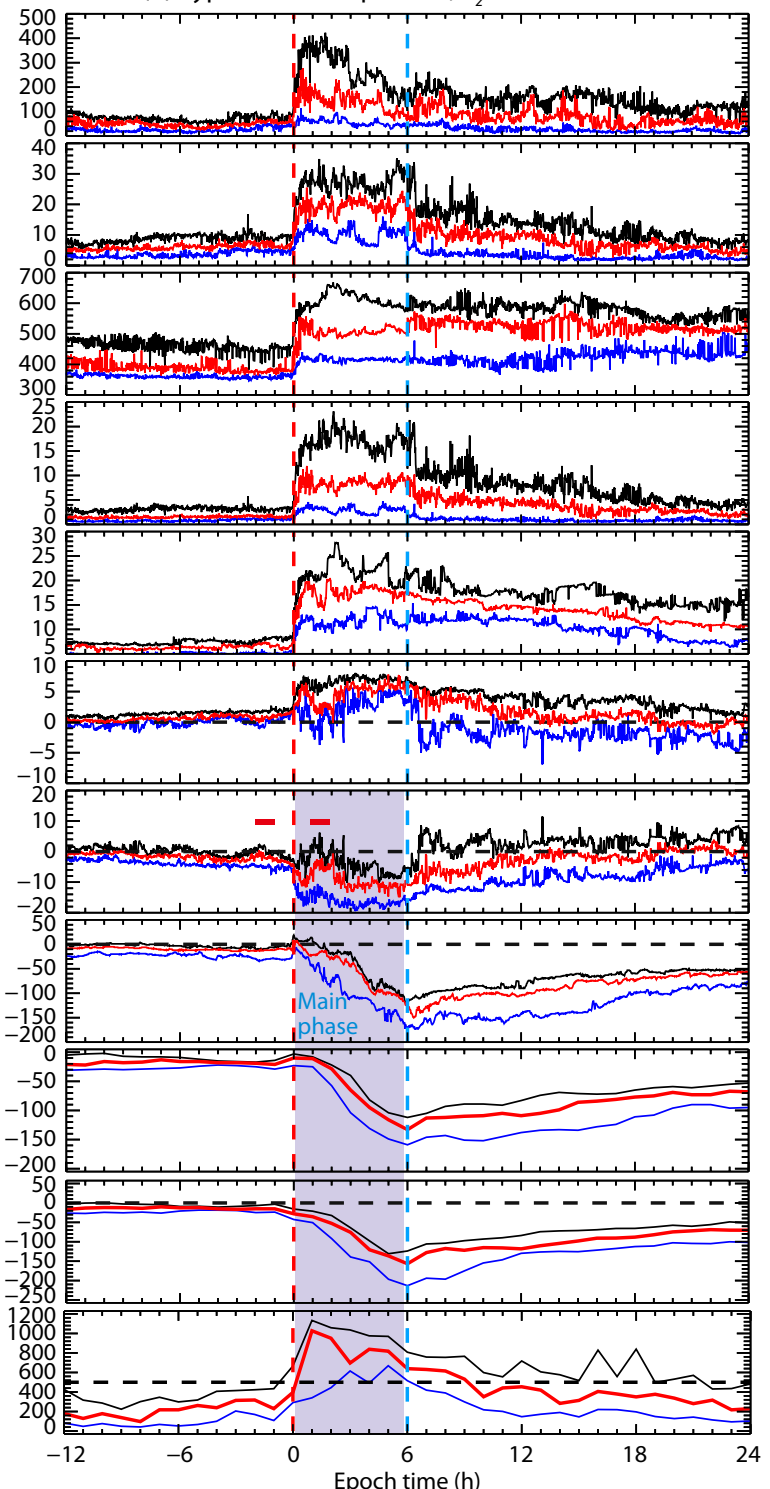

Figure 3. Results of DSEA for Type I and Type III geomagnetic storms. From top to bottom the panels plotted are the plasma temperature, density, velocity, dynamic pressure, the magnetic field intensity, the IMF $B_{z}$, the dawn-dusk electric field, the SYM-H index, Dst index, pressurecorrected $D s t_{0}$, and the $A E$ index. The red dashed line marks the shock arrival time and the sky-blue dashed line represents the $D s t$ minimum time. The light green area represents the initial phase. The purple area represents the main phase.

positive and $E_{y}$ remained negative, with no ring current injection, which led to a high and relatively unchanged value of the SYM-H index, and the storm entered the initial phase. Around time " -3 ", $B_{z}$ rotated from positive to negative and reached its minimum close to time " -2 ". At the same time the $E_{y}$ increased from negative to positive, providing the ring current injection that produced the first main phase and reached its first minimum at time " 0 ". In Figure $4 \mathrm{~b}$, the median value of IMF remained southward both before and after time " -6 ". In the range " -6 to 0 ", the changes of $A E$ in Type II/Type IV were similar to those in Type I/Type III. Meanwhile, $B_{z}$ remained negative, and the continuous positive $E_{y}$ produced ring current injection that caused the decrease of the median value of the SYM-H index from -30 to $-73 \mathrm{nT}$, with its minimum reached at time " 0 ", signaling the first main phase. In the second step of the storm, all parameters of Type II and Type IV showed similar behaviors as in the first step.

From Figure 3 and Figure 4, we notice that the Type I and Type II storms have a clear initial phase (light green area) while the Type III and Type IV storm do not. This can be explained by the Burton equation. Between the time of shock arrival and the time (or the first time) of $D s t_{\min }$, the continuous positive $E_{y}$ for Type III and Type IV storms produced ring current injection that caused a direct main phase. For Type I and Type II storms, $E_{y}$ changed from negative to positive, which resulted in a clear initial phase when the $E_{y}$ was negative, and then the main phase began after the $E_{y}$ became positive.

\section{Discussion}

Ninety-seven intense geomagnetic storms during 1998-2018 
(a) Type Il: two-step storm, $B_{z}$ from " + " to "+"

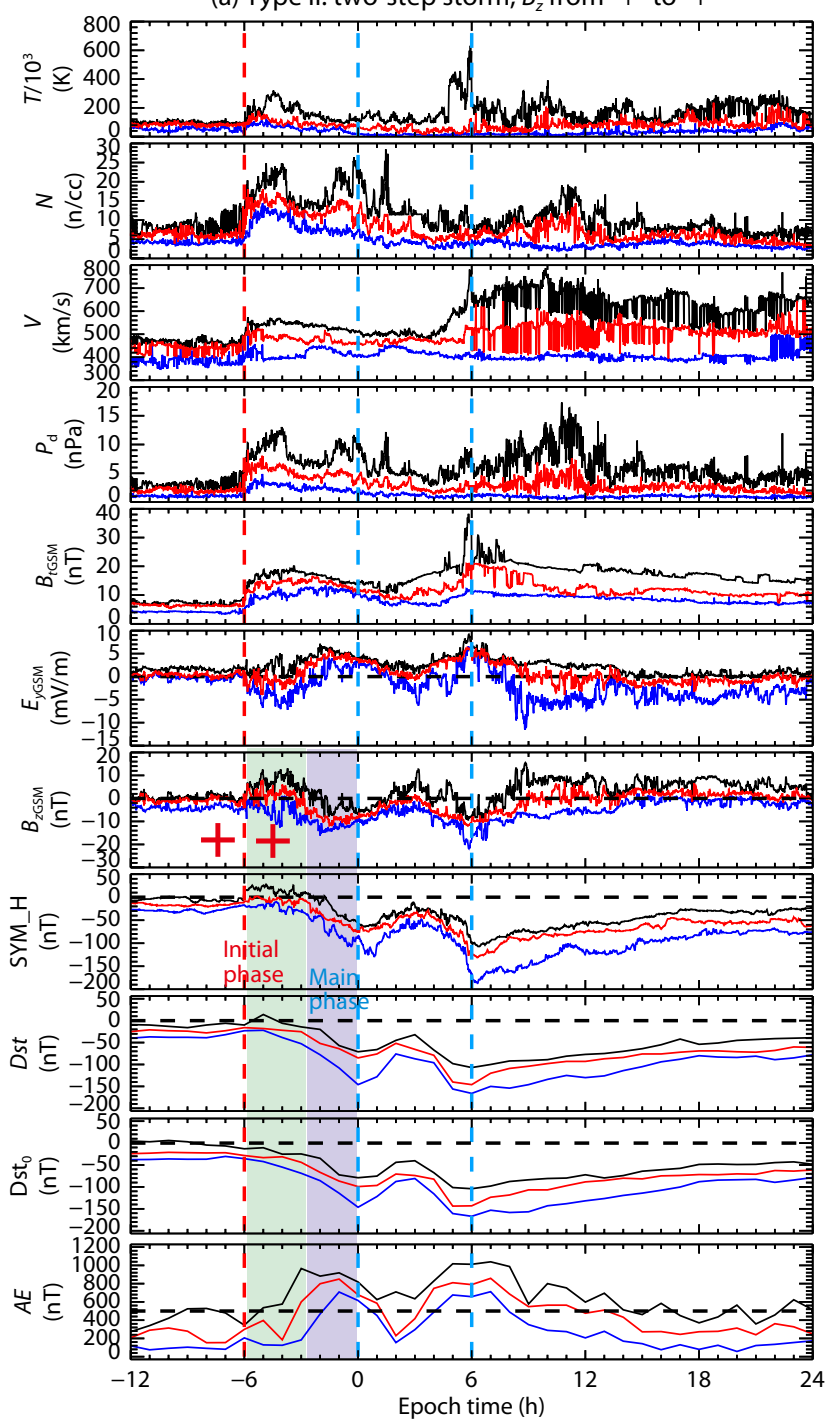

(b) Type IV: two-step storm, $B_{z}$ from "-" to "-"

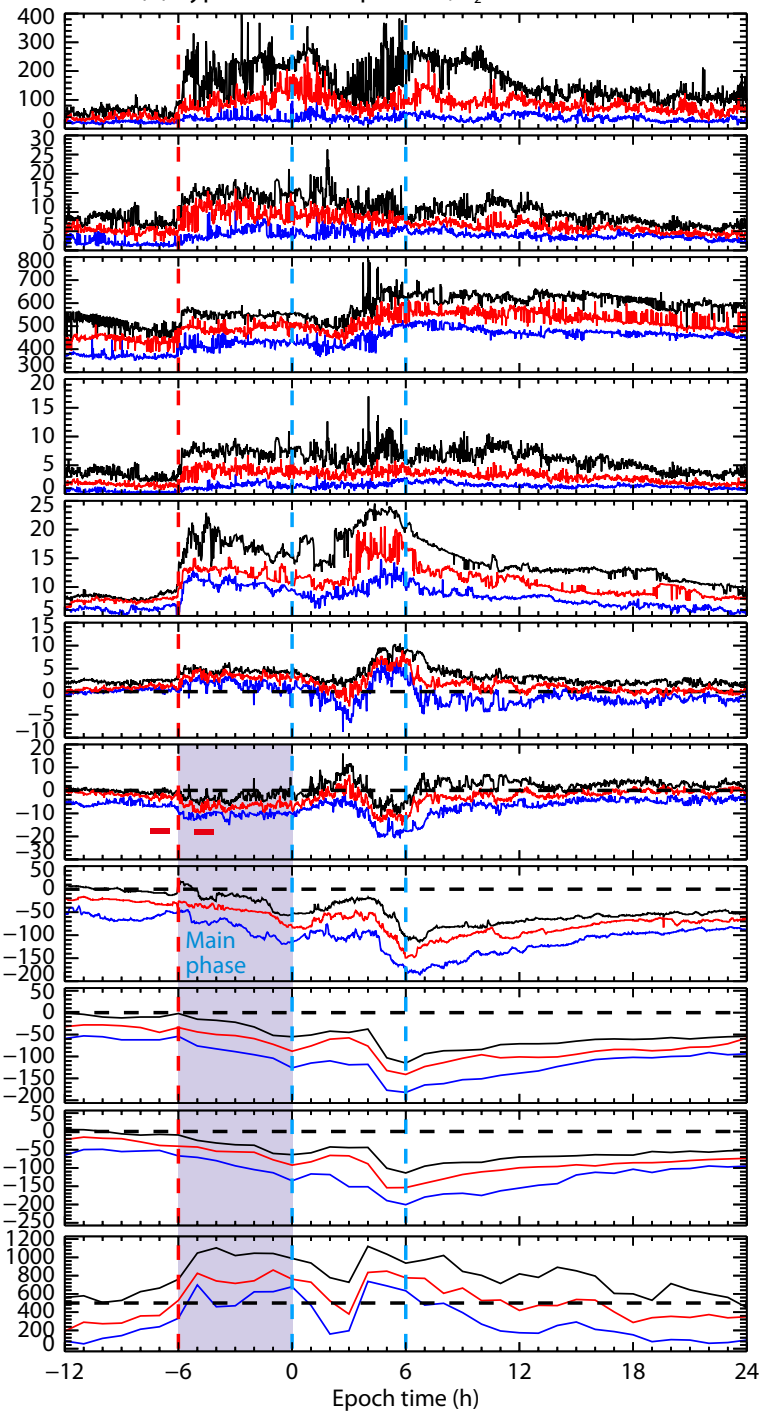

Figure 4. Results of NSEA for Type II and Type IV geomagnetic storms. The red dashed line marks the shock arrival time. The first and second sky-blue lines represent the Dst minima at different steps of the storm. The format is similar to Figure 3.

were studied statistically using the DSEA and NSEA methods applied to data on the interplanetary magnetic field, solar wind parameters, and geomagnetic indices obtained from OMNI.

Our first prominent research finding is that geomagnetic storms with northward IMF both upstream and downstream of the shock arrival (Type I and Type II storms) have a clear initial phase, while storms with southward IMF both upstream and downstream of the shock arrival (Type III and Type IV storms) do not; this finding is illustrated in Figure 5 (which shows only the IP shocks and driven ICMEs for Type I and Type III). The Burton equation (Burton et al., 1975) can explain this difference. In Figure 6 and Figure 7, between the time of shock arrival and the time (or the first time) of $D s t_{\min }$, the continuous positive $E_{y}$ for Type III and Type IV storms produced ring current injection that caused a direct main phase. In Figure $6 a$, Figure $7 a$, and Figure $7 c$, it can be seen that for a long time after the time of shock arrival, the injection term $F(E)$ is zero, with no ring current injection to cause an initial phase. In Figure $6 \mathrm{~b}$, Figure $7 \mathrm{~b}$ and Figure $7 \mathrm{~d}$, it can be seen that the abso- lute value of the injection term is positive; thus, ring current injection dominated this interval. As a result, the main phase began directly.

The second prominent finding is that when $B_{z}$ is negative before and after the IP shock arrival, the $A E$ index rises rapidly, and its maximum value usually exceeds $1,000 \mathrm{nT}$, triggering a strong substorm, as shown in Figure 5 . It is worth pointing out that intense geomagnetic storms and substorms usually have complex and intervening interplanetary drivers (Lee et al., 2007, 2010; Lyons et al., 2008). On the one hand, Lee et al. (2007) has shown many cases in which solar wind changes do not trigger substorms, and the possible reasons includes the lack of insufficient substorm growth phase development prior to the potential triggering change, the inherently nontriggering solar wind change, or the nullifying effect may occur when more than one solar wind quantity change simultaneously. To trigger substorms, the solar wind variations need to reduce the convection strength within the inner plasma sheet. On the other hand, storm-time substorms can be triggered 


\section{Interplanetary shock structure}
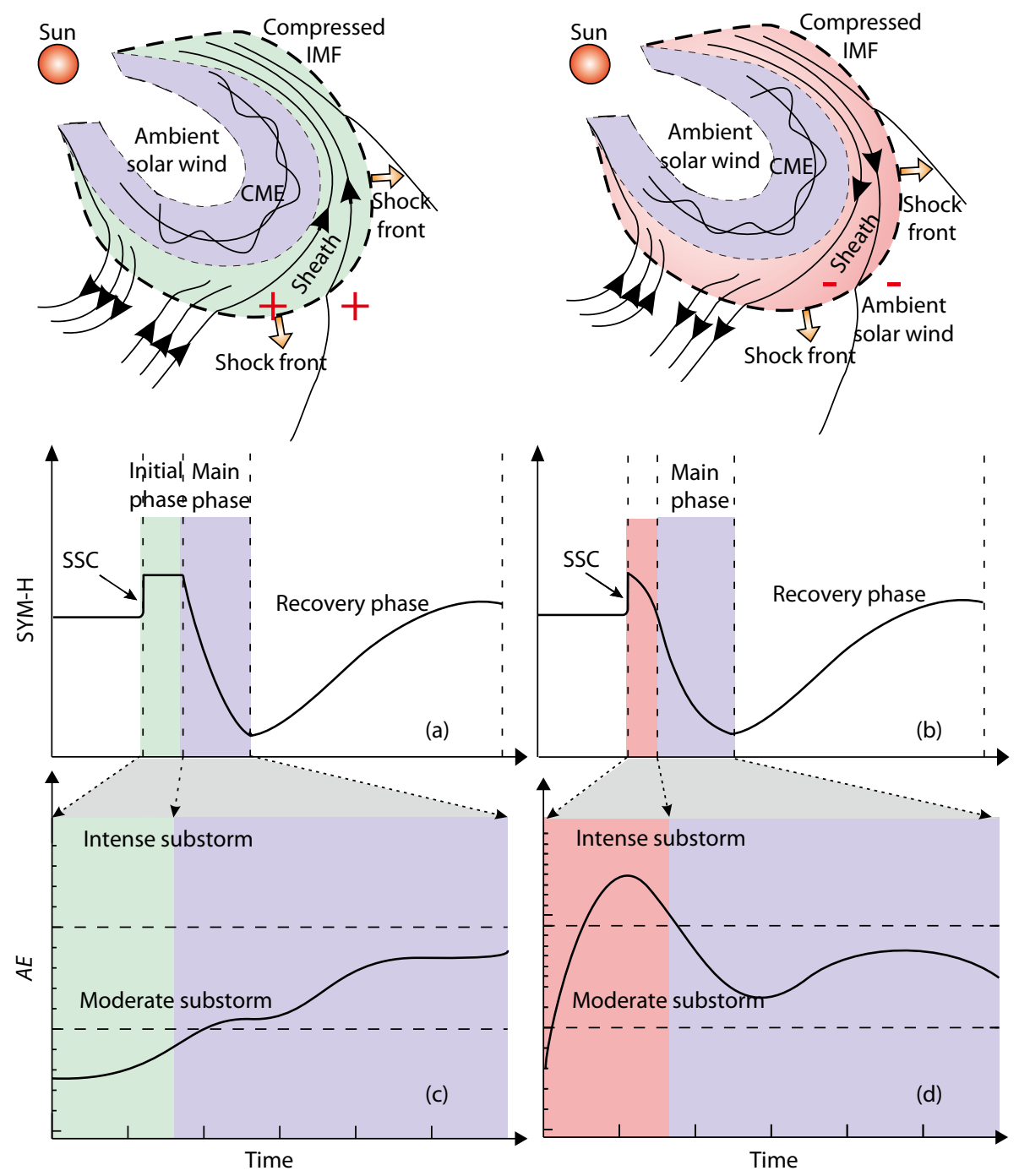

Figure 5. Schematic diagram of the Type I and Type III IP shocks and driven CMEs. The schematic diagram of substorms characteristics during the initial phase and the main phase of the magnetic storms.

when the magnetosphere is impacted by a substantial increase in solar wind dynamic pressure (Lyons et al., 2008), and substorms have been seen to occur under northward IMF conditions during the recovery phase of three strong storms (Lee et al., 2010). The results of our study are related to the preconditioning of the magnetosphere by SW and IMF, and since IMF changes are accompanied by simultaneous changes in other SW variables such as density and velocity, it is usually not easy to tell which SW/IMF parameter dominates in determining the magnetospheric phenomenon under consideration, especially when we focus on each case instead of on statistically superposed epoch analysis results.

The third prominent feature is that the time of minimum $D s t_{0}$ is not identical to the time of minimum $B_{z}$. In Figure 1 and Figure 2, the time of minimum $B_{z}$ is $1-5$ hours earlier than the time of minimum $D s t_{0}$. For statistical study, the $D s t_{0}$ usually reaches its minimum at least an hour after $B_{z}$, although the time is scaled between reference points. Similarly, Gonzalez and Echer (2005) analysed 64 intense geomagnetic storms and found that the average delay between peak $B_{z}$ and peak Dst values is $\sim 2 \mathrm{~h}$. Zhang JC et al. (2006) compared solar wind features of geomagnetic storm events at solar minimum and maximum by performing SEA on 549 storms and found that the peak time difference is $0.3-1.0$ hour between the average IMF $B_{z}$ and $D s t_{\min }$. The time difference also can be explained by the Burton equation (Burton et al., 1975). As can be seen in equation (2), when the absolute value of the injection term $F(E)$, which we averaged to hourly resolution for comparison with our other hourly parameters, is larger than the absolute value of the decay term $a D s t_{0}$, the $\mathrm{d} D s t_{0} / \mathrm{d} t$ is minus and the $D s t_{0}$ index will continue to decrease. Otherwise, if the absolute value of the injection term $F(E)$ is smaller than the absolute value of the decay term $a D s t_{0}$, the $\mathrm{d} D s t_{0} / \mathrm{d} t$ is positive and $D s t_{0}$ will began to increase. The time at which $\mathrm{d} D s t_{0} / \mathrm{d} t$ changes its sign is not necessarily the same as the time of minimum $B_{z}$. This is shown quantitatively in Figure 6 and Figure 7, which give each term in the Burton equation for two cases of the one-step storm (in 
(a) 1998/06/26 one-step storm, $B_{z}$ from " + " to " + "

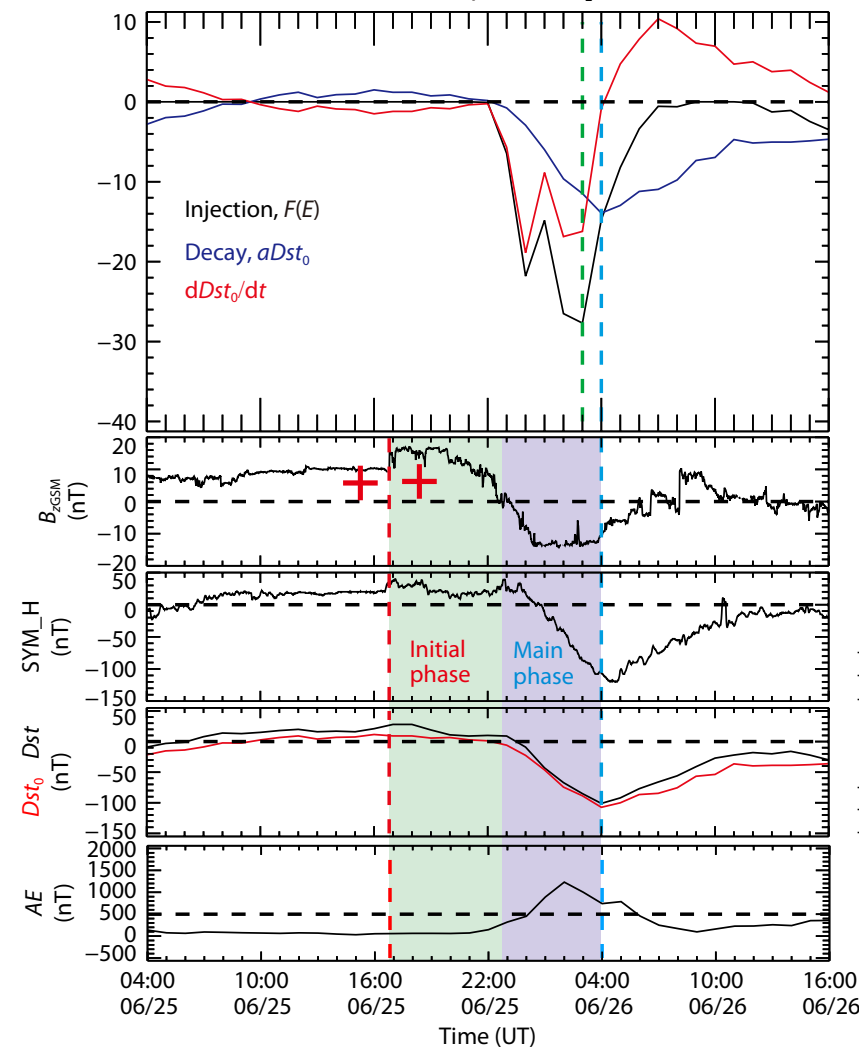

(b) 1998/08/06 one-step storm, $B_{z}$ from "-" to "-"

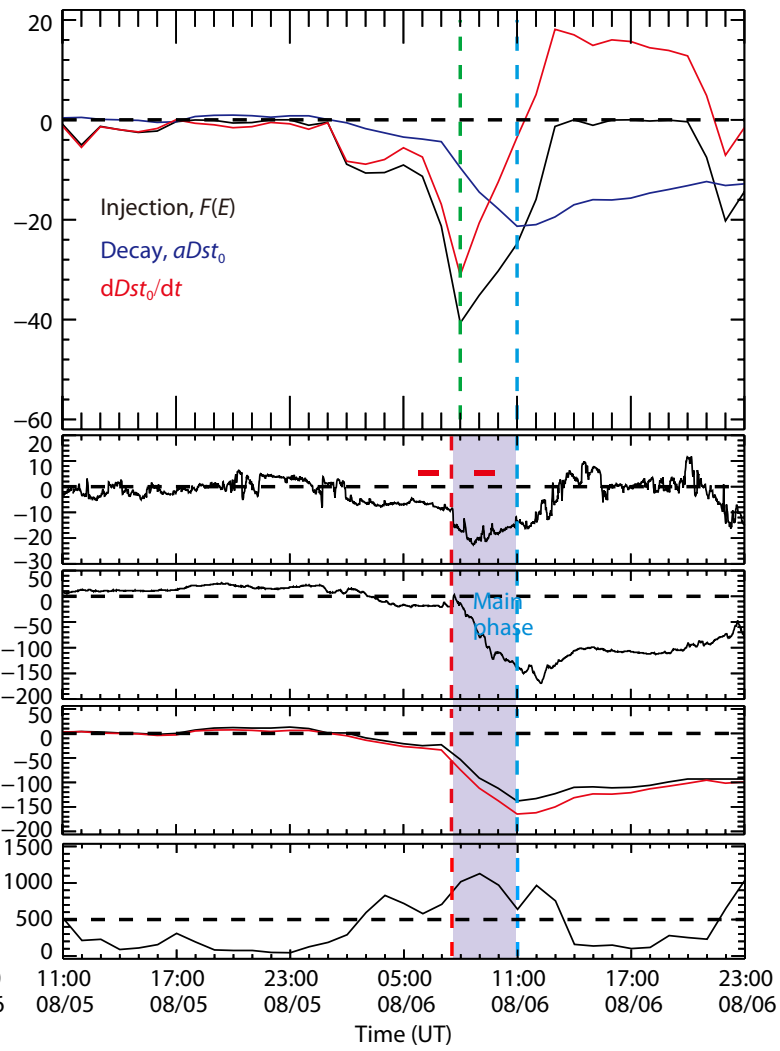

Figure 6. Each term in the Burton equation for the one-step storm case with northward/southward IMF both upstream and downstream of the IP shock Panel (a) / Panel (b). The hourly averaged injection $F(E)$, decay, and the sum of these two terms are shown as black, blue, and red lines, respectively. The green/sky-blue vertical dashed line denotes the time when $B_{z} / D s t_{0}$ reaches its minimum. The red dashed line marks the shock arrival time.

Figure 6), and Type I, Type II, Type III, and Type IV storms (in Figure 7).

Figure 8 shows the pressure-corrected $D s t_{0}$ index and 1-hour step predicted $D s t^{*}$ for Type I, Type II, Type III, and Type IV storms. The black line is $D s t_{0}$, the red dashed line shows the 1-hour step predicted $D s t^{*}$ according to the Burton equation, i.e., we use the pressure-corrected $D s t_{0}$ index and solar wind and IMF parameters of the current hour to predict the Dst $t_{0}$ index of the next hour. It can be seen that the 1-hour step predicted $D s t^{*}$ is consistent with the pressure-corrected $D s t_{0}$ for the sixstorm types, demonstrating that the Burton equation can reveal the characteristics of $D s t_{0}$ variation and therefore the physical mechanisms of these four types of magnetic storm.

\section{Conclusion}

In this study, we systematically analyzed the properties of the interplanetary magnetic field, the solar wind parameters, the dawndusk electric field, and the Dst and $A E$ indices by using DSEA and NSEA methods for four different types of geomagnetic storm. We focused primarily on the morphology of the initial phase of the storms and the intensity of substorms under different interplanetary conditions, details that have generally been ignored in previous studies. Our conclusions are summarized as follows:

(1) Geomagnetic storms with northward IMF both upstream and downstream of the IP shock (Type I and Type II storms) have a clear initial phase; geomagnetic storms with southward IMF both upstream and downstream of the IP shock (Type III and Type IV storms) do not. The continuous positive $E_{y}$ on both sides of the IP shock for Type III and Type IV storms produces ring current injection that directly causes a main phase. The main phase begins immediately after the compression. In Type I and II storms, however, $E_{y}$ changes from negative to positive after the planetary shock, which results in a clear initial phase while the $E_{y}$ is negative; the storm main phase is initiated only after the $E_{y}$ sign changes to be positive.

(2) The IMF is an important controlling factor in affecting the intensity characteristics of substorms. When $B_{z}$ is positive before and after the IP shock arrival, the $A E$ index changes gently during the initial phase of geomagnetic storms; usually, its median value is maintained at $500-1000 \mathrm{nT}$.

(3) When $B_{z}$ is negative before and after the IP shock arrival, the $A E$ index rises rapidly and reaches its maxmum value approximately 1 $\mathrm{h}$ after SSC, although the time is scaled between reference points. The maximum value of $A E$ is usually greater than $1,000 \mathrm{nT}$, triggering intense substorms.

(4) The time of minimum $D s t_{0}$ is not identical to the time of minimum $B_{z}$. For most cases, Dst $t_{0}$ usually reaches its minimum at least one hour after $B_{z}$ does. The variation trend of $B_{z}$ is highly consist- 

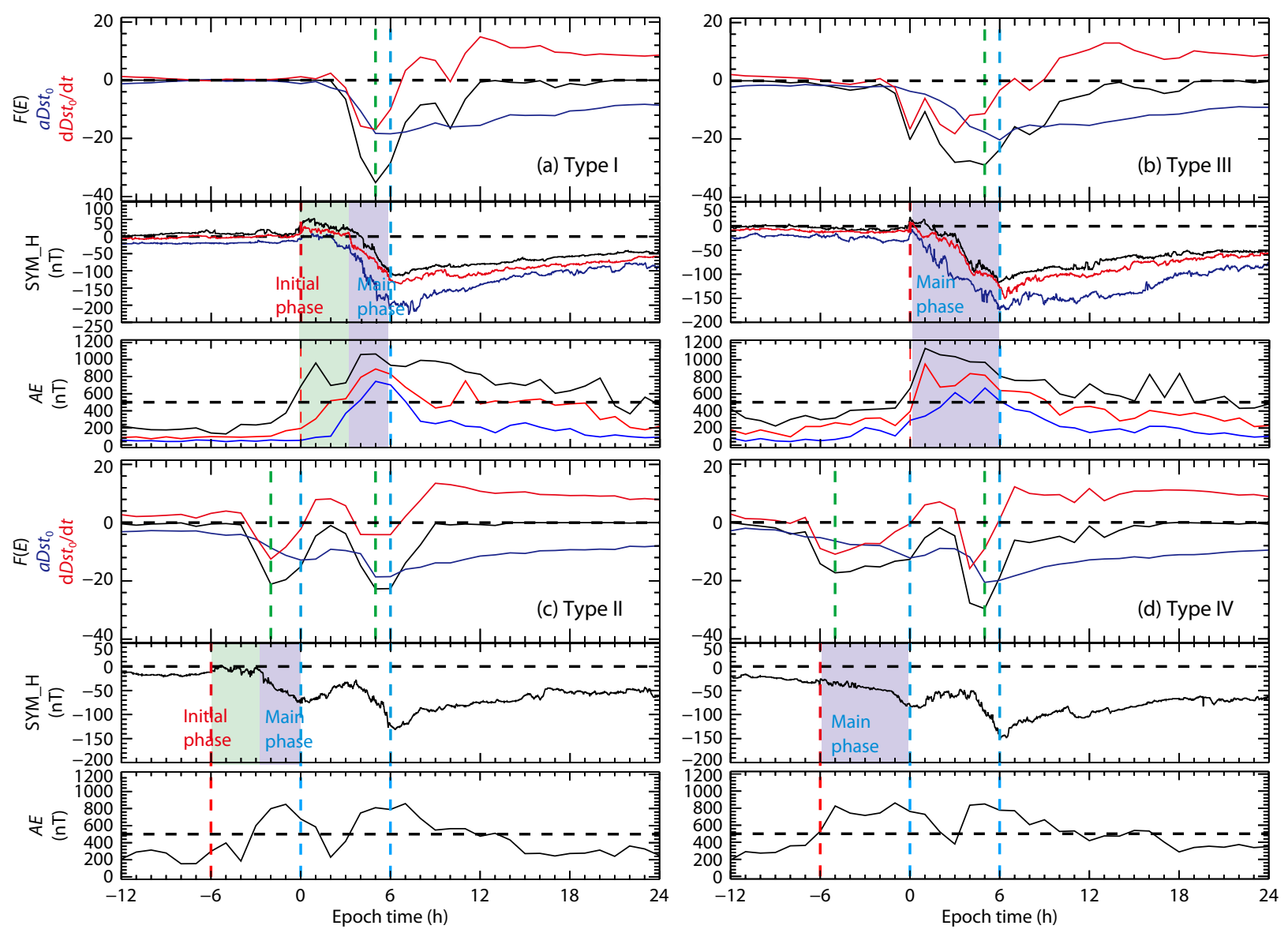

Figure 7. The median value of each term in the Burton equation for Type I, Type II, Type III, and Type IV storms. The format is similar to Figure 6.
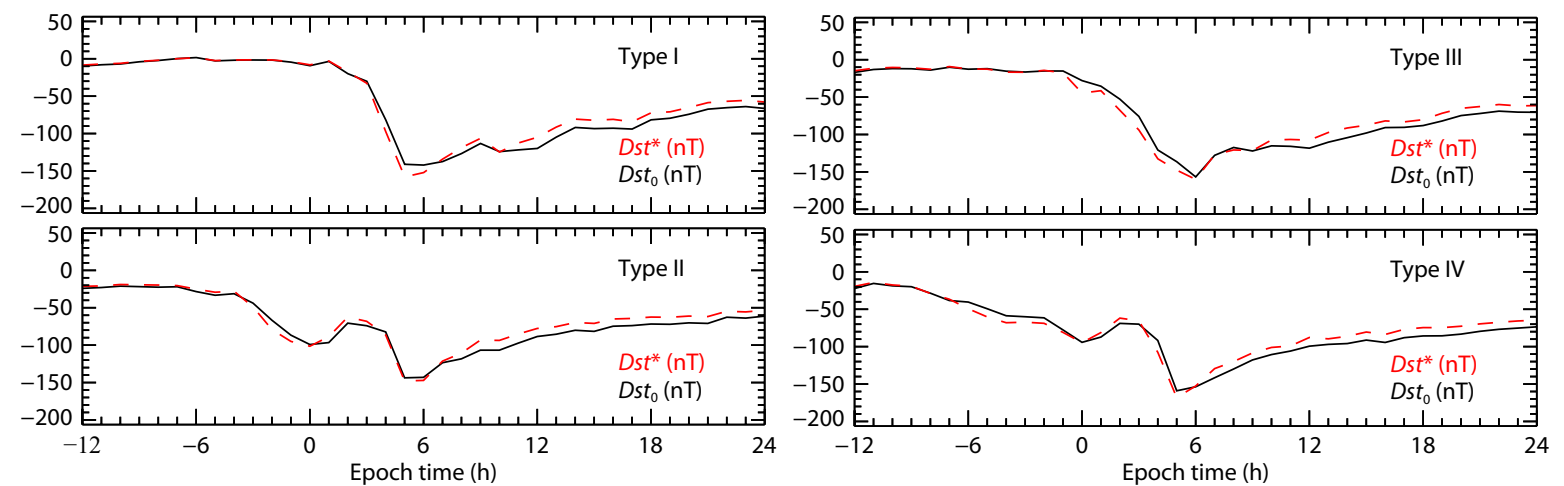

Figure 8. The pressure-corrected $D s t_{0}$ (black line) and 1-hour step predicted $D s t^{*}$ (red dashed line) for Type I, Type II, Type III, and Type IV storms.

ent with the morphology of geomagnetic storms, and the time at which $B_{z}$ reaches its minimum is at least 1 hour ahead of the time at which the magnetic storm (i.e., Dst index) reaches its minimum. Therefore, $B_{z}$ can be used as an important input parameter for geomagnetic storm modeling to predict storm morphology change and intensity and can be helpful in improving the forecast accuracy of geomagnetic storm models.

\section{Acknowledgments}

We acknowledge the OMNI web (ftp://spdf.gsfc.nasa.gov/pub/ data/omni/high_res_omni/sc_specific/) and the Geomagnetic Data Service web (http://wdc.kugi.kyoto-u.ac.jp/wdc/Sec3.html) for providing us OMNI and Geomagnetic indices data.

\section{References}

Akasofu, S. I., and Chapman, S. (1963). The development of the main phase of magnetic storms. J. Geophys. Res., 68(1), 125-129. https://doi.org/10.1029/JZ068i001p00125

Brueckner, G. E., Delaboudiniere, J. P., Howard, R. A., Paswaters, S. E., St. Cyr, O. C., Schwenn, R., Lamy, P., Simnett, G. M., Thompson, B., and Wang, D. (1998). 
Geomagnetic storms caused by coronal mass ejections (CMEs): March 1996 through June 1997. Geophys. Res. Lett., 25(15), 3019-3022. https://doi.org/10.1029/98GL00704

Burton, R. K., McPherron, R. L., and Russell, C. T. (1975). An empirical relationship between interplanetary conditions and Dst. J. Geophys. Res., 80(31), 4204-4214. https://doi.org/10.1029/JA080i031p04204

Cane, H. V., Richardson I. G., and St. Cyr, O. C. (2000). Coronal mass ejections, interplanetary ejecta and geomagnetic storms. Geophys. Res. Lett., 27(21), 3591-3594. https://doi.org/10.1029/2000GL000111

Dessler, A. J., and Parker, E. N. (1959). Hydromagnetic theory of geomagnetic storms. J. Geophys. Res., 64(12), 2239-2252. https://doi.org/10.1029/JZ064i012p02239

Farrugia, C. J., Jordanova, V. K., Thomsen, M. F., Lu, G., Cowley, S. W. H., and Ogilvie, K. W. (2006). A two-ejecta event associated with a two-step geomagnetic storm. J. Geophys. Res., 111(A11), A11104. https://doi.org/10.1029/2006JA011893

Gonzalez, W. D., Joselyn, J. A., Kamide, Y., Kroehl, H. W., Rostoker, G., Tsurutani, B. T., and Vasyliunas, V. M. (1994). What is a geomagnetic storm?. J. Geophys. Res., 99(A4), 5771-5792. https://doi.org/10.1029/93JA02867

Gonzalez, W. D., Tsurutani, B. T., and Clúa de Gonzalez, A. L. (1999). Interplanetary origin of geomagnetic storms. Space Sci. Rev., 88(3-4), 529-562. https://doi.org/10.1023/A:1005160129098

Gonzalez, W. D., and Echer, E. (2005). A study on the peak Dst and peak negative Bz relationship during intense geomagnetic storms. Geophys. Res. Lett., 32(18), L18103. https://doi.org/10.1029/2005GL023486

Gopalswamy, N., Lara, A., Lepping, R. P., Kaiser, M. L., Berdichevsky, D., and St. Cyr, O. C. (2000). Interplanetary accelera-tion of coronal mass ejections. Geophys. Res. Lett., 27(2), 145-148. https://doi.org/10.1029/1999GL003639

Gosling, J. T., McComas, D. J., Phillips, J. L., and Bame, S. J. (1991). Geomagnetic activity associated with earth passage of interplanetary shock disturbances and coronal mass ejections. J. Geophys. Res., 96(A5), 7831-7839. https://doi.org/10.1029/91JA00316

Hajra, R., Tsurutani, B. T., Echer, E., Gonzalez, W. D., and Gjerloev, J. W. (2016). Supersubstorms (SML<- $2500 \mathrm{nT}$ ): Magnetic storm and solar cycle dependences. J. Geophys. Res., 121(8), 7805-7816. https://doi.org/10.1002/2015JA021835

Kamide, Y., Yokoyama, N., Gonzalez, W., Tsurutani, B. T., Daglis, I. A., Brekke, A., and Masuda, S. (1998). Two-step devel-opment of geomagnetic storms. J. Geophys. Res., 103(A4), 6917-6922. https://doi.org/10.1029/97JA03337

Lakhina, G. S., Alex, S., Mukherjee, S., and Vichare, G. (2006). On magnetic storms and substorms. In Proceedings of ILWS Workshop 2006. GOA.

Le, G. M., Tang. Y. H., Zheng, L., and Liu, L. G. (2010). An analysis of interplanetary sources of geomagnetic storm during November 7-8, 1998. Chin. Sci. Bull., 55(9), 851-856. https://doi.org/10.1007/s11434-009-0228-x

Lee, D. Y., Lyons. L. R., Weygand. J. M., and Wang, C. P. (2007). Reasons why some solar wind changes do not trigger sub-storms. J. Geophys. Res., 112(A6), A06240. https://doi.org/10.1029/2007JA012249

Lee, D. Y., Choi, K. C., Ohtani, S., Lee, J. H., Kim, K. C., Park, K. S., and Kim, K. H. (2010). Can intense substorms occur under northward IMF conditions?. J. Geophys. Res., 115(A1), A01211. https://doi.org/10.1029/2009JA014480

Lyons, L. R., Lee, D. Y., Zou, S., Wang, C. P., Kozyra, J. U., Weygand, J. M., and Mende, S. B. (2008). Dynamic pressure enhancements as a cause of largescale stormtime substorms. J. Geophys. Res., 113(A8), A08215. https://doi.org/10.1029/2007JA012926

Ma, X.-H., Zong, Q.-G., and Liu, Y. (2019). The intense substorm incidence in response to interplanetary shock impacts and influence on energetic electron fluxes at geosynchronous orbit. J. Geophys. Res. https://doi.org/10.1029/2018JA026115

O'Brien, T. P., and McPherron, R. L. (2000). An empirical phase space analysis of ring current dynamics: solar wind control of injection and decay. J. Geophys. Res., 105(A4), 7707-7720. https://doi.org/10.1029/1998JA000437

Partamies, N., Juusola, L., Tanskanen, E., Kauristie, K., Weygand, J. M., and Ogawa, Y. (2011). Substorms during different storm phases. Ann Geophys.,
29(11), 2031-2043. https://doi.org/10.5194/angeo-29-2031-2011

Partamies, N., Juusola, L., Tanskanen, E., and Kauristie, K. (2013). Statistical properties of substorms during different storm and solar cycle phases. Ann Geophys., 31(2), 349-358. https://doi.org/10.5194/angeo-31-349-2013

Richardson, I. G., and Zhang, J. (2008). Multiple-step geomagnetic storms and their interplanetary drivers. Geophys. Res. Lett., 35(6), L06S07. https://doi.org/10.1029/2007GL032025

Russell, C. T., McPherron, R. L., and Burton, R. K. (1974). On the cause of geomagnetic storms. J. Geophys. Res., 79(7), 1105-1109. https://doi.org/10.1029/JA079i007p01105

Srivastava, N., and Venkatakrishnan, P. (2004). Solar and interplanetary sources of major geomagnetic storms during 1996-2002. J. Geophys. Res., 109(A10), A10103. https://doi.org/10.1029/2003JA010175

Tsurutani, B. T., and Gonzalez, W. D. (1997). The interplanetary causes of magnetic storms: a review. In B. T. Tsurutani, et al. (Eds.), Magnetic Storms (pp. 77-89). Washington, D. C.: the American Geophysical Union. https://doi.org/10.1029/GM098p0077

Tsurutani, B. T., Hajra, R., Echer, E., and Gjerloev, J. W. (2015). Extremely intense $(\mathrm{SML} \leq-2500 \mathrm{nT})$ substorms: isolated events that are externally triggered?. Ann. Geophys., 33(5), 519-524. https://doi.org/10.5194/angeo-33-519-2015

Vichare, G., Alex, S., and Lakhina, G. S. (2005). Some characteristics of intense geomagnetic storms and their energy budget. J. Geophys. Res., 110(A3), A03204. https://doi.org/10.1029/2004JA010418

Wu, C. C., and Lepping, R. P. (2002). Effects of magnetic clouds on the occurrence of geomagnetic storms: The first 4 years of Wind. J. Geophys. Res., 107(A10), 1314. https://doi.org/10.1029/2001JA000161

Xie, H., Gopalswamy, N., Manoharan, P. K., Lara, A., Yashiro, S., and Lepri, S. (2006). Long-lived geomagnetic storms and coronal mass ejections. J. Geophys. Res., 111(A1), A01103. https://doi.org/10.1029/2005JA011287

Yermolaev, Y. I., Yermolaev, M. Y., Lodkina, I. G., and Nikolaeva, N. S. (2007). Statistical investigation of heliospheric con-ditions resulting in magnetic storms. Cosmic Res., 45(1), 1-8. https://doi.org/10.1134/S0010952507010017

Yermolaev, Y. I., Lodkina, I. G., Nikolaeva, N. S., and Yermolaev, M. Y. (2010a). Statistical study of interplanetary condition effect on geomagnetic storms. Cosmic Res., 48(6), 485-500. https://doi.org/10.1134/S0010952510060018

Yermolaev, Y. I., Nikolaeva, N. S., Lodkina, I. G., and Yermolaev, M. Y. (2010b). Specific interplanetary conditions for CIR-, Sheath-, and ICME-induced geomagnetic storms obtained by double superposed epoch analysis. Ann Geophys., 28(12), 2177-2186. https://doi.org/10.5194/angeo-28-2177-2010

Yue, C., Zong, Q. G., Zhang, H., Wang, Y. F., Yuan, C. J., Pu, Z. Y., Fu, S. Y., Lui, A. T. Y., Yang, B., and Wang, C. R. (2010). Geomagnetic activity triggered by interplanetary shocks. J. Geophys. Res., 115(A5), A00I05. https://doi.org/10.1029/2010JA015356

Yue, C., and Zong, Q. G. (2011). Solar wind parameters and geomagnetic indices for four different interplanetary shock/ICME structures. J. Geophys. Res., 116(A12), A12201. https://doi.org/10.1029/2011JA017013

Zhang, J., Dere, K. P., Howard, R. A., and Bothmer, V. (2003). Identification of solar sources of major geomagnetic storms between 1996 and 2000. Astrophys. J., 582(1), 520-533. https://doi.org/10.1086/344611

Zhang, J. C., Liemohn, M. W., Kozyra, J. U., Thomsen, M. F., Elliott, H. A., and Weygand, J. M. (2006). A statistical com-parison of solar wind sources of moderate and intense geomagnetic storms at solar minimum and maximum. J. Geophys. Res., 111(A1), A01104. https://doi.org/10.1029/2005JA011065

Zhao, H., Zong, Q. G., Wei, Y., and Wang, Y. F. (2011). Influence of solar wind dynamic pressure on geomagnetic $D s t$ index during various magnetic storms. Sci. China Technol. Sci., 54(6), 1445-1454. https://doi.org/10.1007/s11431-011-4319-y

Zhou, X. Y., and Tsurutani, B. T. (2001). Interplanetary shock triggering of nightside geomagnetic activity: substorms, pseu-dobreakups, and quiescent events. J. Geophys. Res., 106(A9), 18957-18967. https://doi.org/10.1029/2000JA003028 